\title{
How to Understand the Planck's Oscillators? Wien Peaks, Planck Distribution Function and Its Decomposition, the Bohm Sheath Criterion, Plasma Coupling Constant, the Barrier of Determinacy, Hubble Cooling Constant. (24.04.2020)
}

\author{
Jiř́i Stávek ${ }^{1}$ \\ ${ }^{1}$ Bazovského 1228, 16300 Prague, Czech republic \\ Correspondence: Jiř́i Stávek, Bazovského 1228, 16300 Prague, Czech republic. E-mail: stavek.jiri@seznam.cz
}

Received: April 23, 2020

Accepted: June 26, 2020

Online Published: July 31, 2020

doi:10.5539/apr.v12n4p63

URL: http://dx.doi.org/10.5539/apr.v12n4p63

\begin{abstract}
In our approach we have combined knowledge of Old Masters (working in this field before the year 1905), New Masters (working in this field after the year 1905) and Dissidents under the guidance of Louis de Broglie and David Bohm. Based on the great works of Wilhelm Wien and Max Planck we have presented a new look on the "Wien Peaks" and the Planck Distribution Function and proposed the "core-shell" model of the photon. There are known many "Wien Peaks" defined for different contexts. We have introduced a thermodynamic approach to define the Wien Photopic Peak at the wavelength $\lambda=555 \mathrm{~nm}$ and the Wien Scotopic Peak at the wavelength $\lambda=$ $501 \mathrm{~nm}$ to document why Nature excellently optimized the human vision at those wavelengths. There could be discovered many more the so-called Wien Thermodynamic Peaks for other physical and chemical processes. We have attempted to describe the so-called Planck oscillators as coupled oscillations of geons and dyons. We have decomposed the Planck distribution function in two parts. Inspired by the Bohm Diffusion and the Bohm Sheath Criterion we have defined the plasma coupling constant that couple oscillations of geons and photons. The difference of the Planck least action of photons and the least action of geons might define the Barrier of Determinacy that create a limit for the resolution in the Microworld. We have newly formulated the Hubble cooling constant and inserted it into the Newton-Zwicky Cooling Law of photons for the description of the cooling of old photons. This proposed view on Planck's Oscillators might open a new way for the description of "Heat" and "Light" processes.
\end{abstract}

Keywords: Planck's Oscillators, Wien Peaks, Planck Distribution Function and Its Decomposition, Wien Photopic and Scotopic Peaks, Coupled Oscillations of Geons and Dyons, Plasma Coupling Constant, the Barrier of Determinacy, Hubble Cooling Constant, "Heat Wave" and "Light Wave", "Nature Loves to Hide"

\section{Introduction}

"Heat" and "Light" are concepts in the center of the research of all generations. Can we bring a new reasonable concept into this Field of research or is this Field already closed? In order to achieve our target, we have to combine knowledge of Old Masters (working in this field before the year 1905), New Masters (working in this field after the year 1905), and Dissidents working on the double helix model of the photon for many years. The key breakthrough was found in the empirical formulae of David Bohm-the Bohm diffusion and the Bohm sheath criterion. These Formulae might guide us into the hidden World of Photons, Geons, and Dyons. There was another important source for our research-how many Wien peaks can be used for the description of the Planck distribution function? Which of those Wien Peaks is the best one for the description in a given situation?

\section{Inspirations from Old Masters and New Masters-How to Understand the Planck's Oscillators?}

We were inspired by many Great Researchers working in this field for generations. In Table 1 we summarized some of those steps in our understanding of those topics. 
Table 1. "Heat" and "Light". How to understand the Planck's Oscillators?

"Heat" and "Light". How to understand the Planck's Oscillators?

1830 - 1850 - The Wave Theory of Heat: A Forgotten Stage in the Transition from the Caloric Theory to Thermodynamics (see Stephen G. Brush in 1970)

1800 - Herschel - radiant heat discovered

1800 - 1850 - Old Masters observed heat waves and their reflection, refraction, diffraction, polarization, interference, etc.

1860 - Kirchhoff: the definition of the black body, Kirchhoff's cavity

After 1860 - Stefan - Boltzmann constant, Boltzmann constant

1894 - Wien - Wien distribution function, Wien displacement law

1900 - Rayleigh - Jeans - equation for low frequencies

1900 - Lummer, Pringsheim, Kurlbaum, Rubens - experimental data

1900 - Planck - Planck distribution function, Planck constant, Planck's oscillators

1905 - Einstein - quantum of light, photoelectric effect

1924 - de Broglie - particle - wave formula

1925 - Bohr, Heisenberg, Schrödinger et al. modern quantum mechanics

After that many New Masters have been working on the quantum mechanics

1950 - Bohm: empirical formula of the Bohm diffusion, the Bohm sheath criterion

Many Great New Masters continue to work on these topics

Wheeler: Thermal geons

J.J. Mareš. P. Hubík, V. Špička: What is Heat? How to describe the Planck's oscillators?

J. Šesták: How to describe the cooling of old photons?

\section{3. "Wien Peaks" and the Planck Distribution Functions}

Max Planck in 1900 derived his Great distribution functions that started a new development of physics:

$$
\begin{aligned}
& B_{\nu}=\frac{2 h \nu^{3}}{c^{2}} \frac{1}{\exp [h \nu /(k T)]-1} \\
& B_{\lambda}=\frac{2 h c^{2}}{\lambda^{5}} \frac{1}{\exp [h c /(\lambda k T)]-1}
\end{aligned}
$$

where $B_{v}$ is the emitted power per unit area per steradian per frequency interval, $B_{\lambda}$ is the emitted power per unit area per steradian per wavelength interval, $\mathrm{h}$ and $\mathrm{k}$ are the Planck and Boltzmann constants and $\mathrm{c}$ is the speed of light.

There are several very inspirative papers on the Wien Peak positions: e.g., J.M. Overduin (2003), M.A. Heald (2003), Z.M. Zhang and X.J. Wang (2010), J.M. Marr and F.P. Francis (2012), S.M. Stewart (2012), A. Delgado-Bonal (2017), S. M. Stewart and R.B. Johnson (2017), and website "Calculation of Blackbody Radiance".

Based on the Wien displacement law several "Wien Peaks" were derived, some of them are given in the Table 2.

Table 2. "Wien Peaks" in the Planck distribution function

\begin{tabular}{lc}
\hline & Wien Peak for the spectral photon radiance in units frequency \\
\hline $2\left(1-\mathrm{e}^{-\mathrm{x}}\right)=\mathrm{x}$ where $\mathrm{x}=\mathrm{h} v / \mathrm{kT}$ & $\mathrm{x}=\mathrm{a}_{2}=1.59362426004$ \\
\hline $3\left(1-\mathrm{e}^{-\mathrm{x}}\right)=\mathrm{x}$ where $\mathrm{x}=\mathrm{h} v / \mathrm{kT}$ & Wien Peak for the spectral radiance in units frequency \\
\hline & $\mathrm{x}=\mathrm{a}_{3}=2.82143937212$ \\
\hline $4\left(1-\mathrm{e}^{-\mathrm{x}}\right)=\mathrm{x}$ where $\mathrm{x}=\mathrm{h} v / \mathrm{kT}$ & $\mathrm{Wien} \mathrm{Peak}$ for the spectral photon radiance in units wavelength \\
\hline & Wien Peak for the spectral radiance in units wavelength \\
\hline $5\left(1-\mathrm{e}^{-\mathrm{x}}\right)=\mathrm{x}$ where $\mathrm{x}=\mathrm{h} v / \mathrm{kT}$ & $\mathrm{x}=\mathrm{a}_{5}=4.96511423174$ \\
\hline
\end{tabular}

Several researchers developed another "Wien Peaks" in order to describe different contexts of the application of the Planck distribution function. Which of those "Wien Peaks" have been used by real detectors in the Nature? 


\section{4. "Wien Photopic Peak", "Wien Scotopic Peak", "Wien Thermodynamic Peaks"}

The existence of several Wien Peaks leads to a question-which of those Wien Peaks should be used for a given situation? E.g., there is a paradox for the human vision (see e.g. B. H. Soffer \& D. Lynch in 1999, A. Delgado-Bonal and J. Martin-Torres in 2016). The Wien Peak for the spectral radiance in units of frequency lays in the infrared region. Why is not the maximum efficiency of human photopic vision in infrared range but at the wavelength $555 \mathrm{~nm}\left(=5.4 * 10^{14} \mathrm{~Hz}\right.$, see the definition of the SI unit CANDELA)? Why Nature tuned the maximum of the photopic vision to the wavelength $555 \mathrm{~nm}$ ? The answer is very surprising and documents the Great Art of our Nature-we can modify the Planck distribution function if we insert to that function the frequency $v$ divided by the value $\mathrm{a}_{2}=1.5936 \ldots$. By this modification we find the maximum of the Solar spectrum both for the number of photons and their energy at the Solar temperature $\mathrm{T}=5800 \mathrm{~K}$ at $\lambda_{\max }=555 \mathrm{~nm}$ :

$$
B_{\nu}=\frac{2 h}{c^{2}}\left(\frac{\nu}{a_{2}}\right)^{3} \frac{1}{\exp \left[h \nu /\left(a_{2} k T\right)\right]-1}
$$

The discovery of this Wien Photopic Peak stimulated us to search for more Wien Peaks based thermodynamic arguments and we have found one formula for the value $\mathrm{a}_{5}=4.9651 \ldots$ leading to the maximum $\lambda_{\max }=555 \mathrm{~nm}$ :

$$
E=\left(a_{5}-\frac{1}{2}\right) k T+\frac{1}{2} k T
$$

We can conclude that the human eye is the great thermodynamic detector. For the photopic vision under well-lit conditions part of the photon energy change to "heat quantum" and the rest of the photon energy creates the "light" in the human eye. In the case of the scotopic vision under low-light level all photon energy is transformed into the "light". This maximum at $501 \mathrm{~nm}$ we can call the "Wien Scotopic Peak". This effect of the scotopic vision is called the Purkinje effect after the Great Old Master Jan Evangelista Purkyně.

We might similarly define other "Wien Thermodynamic Peaks" that could be found in some other physical, chemical or biochemical processes-Table 3 .

Table 3. "Wien Thermodynamic Peaks"

\begin{tabular}{ll}
\hline Wien Thermodynamic Peaks for the spectral radiance in units frequency for $\mathbf{T}=\mathbf{5 8 0 0} \mathbf{K}$ & Effect \\
\hline $\mathrm{E}_{\mathrm{v}}=\mathrm{a}_{3} \mathrm{kT}$ & $\begin{array}{l}\text { Maximal "heat" from photons, } \\
\text { Herschel Peak at } 879 \mathrm{~nm}\end{array}$ \\
$\mathrm{E}_{\mathrm{v}}=\left(\mathrm{a}_{3}-1 / 2\right) \mathrm{kT}+1 / 2 \mathrm{kT}$ & $1069 \mathrm{~nm} ?$ \\
$\mathrm{E}_{\mathrm{v}}=\left(\mathrm{a}_{3}-3 / 2\right) \mathrm{kT}+3 / 2 \mathrm{kT}$ & $1877 \mathrm{~nm} ?$ \\
$\mathrm{E}_{\mathrm{v}}=\left(\mathrm{a}_{3}-5 / 2\right) \mathrm{kT}+5 / 2 \mathrm{kT}$ & $7717 \mathrm{~nm}$ gravitation effect \\
\hline Wien Thermodynamic Peaks for the spectral radiance in units wavelength for $\mathbf{T}=\mathbf{5 8 0 0} \mathbf{K}$ & \\
\hline $\mathrm{E}_{\lambda}=\mathrm{a}_{5} \mathrm{kT}$ & $499 \mathrm{~nm}$ scotopic vision \\
$\mathrm{E}_{\lambda}=\left(\mathrm{a}_{5}-1 / 2\right) \mathrm{kT}+1 / 2 \mathrm{kT}$ & $555 \mathrm{~nm}$ photopic vision \\
$\mathrm{E}_{\lambda}=\left(\mathrm{a}_{5}-3 / 2\right) \mathrm{kT}+3 / 2 \mathrm{kT}$ & $716 \mathrm{~nm} ?$ \\
$\mathrm{E}_{\lambda}=\left(a_{5}-5 / 2\right) \mathrm{kT}+5 / 2 \mathrm{kT}$ & $1006 \mathrm{~nm} ?$ \\
$\mathrm{E}_{\lambda}=\left(a_{5}-7 / 2\right) \mathrm{kT}+7 / 2 \mathrm{kT}$ & $1693 \mathrm{~nm} ?$ \\
$\mathrm{E}_{\lambda}=\left(a_{5}-9 / 2\right) \mathrm{kT}+9 / 2 \mathrm{kT}$ & $5333 \mathrm{~nm} ?$ \\
\hline
\end{tabular}

We can conclude that a given detector is able split the same photon energy packet into frequency or wavelength packets. There is an analogy - we can withdraw our money in the "USD" energy packets or "Euro" energy packets in banknotes with different values. There might be a rule in the Nature - sometimes it is better to pay using the "USD" energy packet, in other circumstances we should pay using the "Euro" energy packet.

We want to pass this scenario into the hands of Readers of this Journal better educated in Thermodynamics, processes in physics, chemistry and biology to estimate this model in other situations.

\section{Decomposition of the Planck Distribution Function}

We would like to extract some more information about the internal structure of the Planck Distribution Function. Therefore, we propose to decompose this Function in two parts as: 


$$
B_{\nu}=\frac{2 h \nu^{3}}{c^{2}}\left[\frac{1}{\exp [h \nu /(k T)]-1}\right]=\frac{2 h \nu^{3}}{c^{2}}\left[\exp [-h \nu /(k T)]+\frac{\exp [-h \nu /(k T)]}{\exp [h \nu /(k T)]-1}\right]
$$

This operation splitted the Planck Distribution Function into the Wien Distribution Function plus one new distribution function. We estimate that the Wien Distribution Function could describe geons and the second part might describe dyons. The Wien "approximation" for photons might be precise distribution function for geons. We estimate that the particle called "photon" might create simultaneously two coupled waves - one "heat wave" and one "light wave".

At low frequencies - in the domain of the Rayleigh-Jeans Law - dyon oscillations dominate in the blackbody radiation. Based on this Rayleigh-Jeans Law at higher frequencies we approach to the "ultraviolet catastrophe".

At very high frequencies - in the area of the Wien Law - geon oscillations play the dominate role.

In the middle range of frequencies - the territory of the Planck Law - both dyon and geon oscillators create together the "quantum effect" through their synergic co-oscillation.

We want to pass this model into the hands of Readers of this Journal better educated in the mathematics to describe this synergic effect of dyons and geons. This joint synergic oscillation might explain the observed "quanta" of energy.

In order to get more information from the Microworld we will employ the Bohm Diffusion and the Bohm sheath criterion.

\section{The Bohm Sheath Criterion, the Bohm Diffusion, Beta of Plasma and Geon Properties}

David Bohm in 1947 - 1954 conjectured several important formulae for plasma that might be useful for the description of geons - the Bohm Sheath Criterion and the Bohm Diffusion (e.g., K.U. Riemann in 1991 and N. Sternberg and V. Godyak in 2007). This concept was recently applied by Jiří Stávek (2020). In this model the geon and dyon form together the photon - a coupled oscillator of the "heat wave" and the "light" wave:

$$
m \quad 2 \text { c } V_{S t}=k T
$$

where $\mathrm{m}$ is the geon mass (identical to the photon mass), $\mathrm{c}$ is the light speed, $\mathrm{V}_{\mathrm{St}}$ is the Bohm speed describing the perpendicular vibration speed ("heat content"), $\mathrm{k}$ is the Boltzmann constant and $\mathrm{T}$ is temperature.

David Bohm in 1949 conjectured the Bohm diffusion scaling for the diffusion of plasma across a magnetic field with the magnetic field strength $B$ :

$$
D_{B}=\frac{k_{B} T}{16 B e}
$$

The meaning of this empirical Bohm diffusion is actively discussed in the literature. The number 16 is only empirical constant and might be changed by a future modification.

We will extract from this equation amplitude $\mathrm{A}$, wavelength $\lambda$ and volume of geons $\mathrm{V}_{\mathrm{G}}$ as:

$$
\begin{gathered}
A=\frac{\lambda}{2 \pi}=\frac{1}{2 \pi} \frac{k_{B} T}{2} \frac{1}{B e c} \\
\lambda=\frac{k_{B} T}{2} \frac{1}{B e c} \\
V_{G}=\lambda \frac{k_{B}^{2} T^{2}}{16 \pi B^{2} e^{2} c^{2}}=\frac{2 \mu_{0}}{B^{2}} \frac{k_{B} T}{2}
\end{gathered}
$$

Because the geon is in the equilibrium with the magnetic field strength B in the surroundings, we can express Beta of plasma as: 


$$
\beta=1=\frac{\text { pressure of geon }}{\text { magnetic pressure }}=\frac{\frac{\text { energy of geon }}{\text { volume of geon }}}{\text { magnetic pressure }}=\frac{\frac{k_{B} T}{2} \frac{1}{V_{G}}}{\frac{B^{2}}{2 \mu_{0}}}
$$

After some re-arrangement we will get an expression for the geon wavelength $\lambda$ for the geon the helical path with the Weber speed $\mathrm{c}_{\mathrm{W}}=\sqrt{2} \mathrm{c}$ and its energy $\mathrm{E}=\mathrm{kT}$ as:

$$
\lambda=8 \pi \mu_{0} e^{2} c \frac{c}{k T}=\frac{h_{G} c}{k T}=\frac{0.005277515 \ldots\left[m \left[\begin{array}{ll}
m & K
\end{array}\right.\right.}{T}
$$

This is the displacement law for geons as a part of photons - an analogy with the Wien's displacement law for photons.

The quantum of geon action can be evaluated as:

$$
h_{G}=8 \pi \mu_{0} e^{2} c=2.43048 \ldots *{ }^{*} 10^{-34} \mathrm{~J} \mathrm{~s}
$$

One relation connecting the Planck least action $\mathrm{h}$ of photons, the geon least action $\mathrm{h}_{\mathrm{G}}$ and the fine structure constant $\alpha$ was found by Jiří Stávek (2020) as:

$$
\alpha=\frac{h_{G}}{16 \pi h}
$$

\section{The Plasma Coupling $\Gamma$ for Geons}

The plasma coupling $\Gamma$ is defined as a ratio of the Coulomb energy to the thermal one. For geons we can write:

$$
\Gamma=\frac{E_{C}}{k T}=\frac{\frac{1}{4 \pi \varepsilon_{0}} \frac{e^{2} 2 \pi}{\lambda_{G}}}{k T}=\frac{e^{2}}{2 \varepsilon_{0} \lambda_{G} k T}=\frac{e^{2}}{2 \varepsilon_{0} h_{G} c}=\frac{e^{2} \mu_{0} c^{2}}{2 h_{G} c}=\frac{1}{16 \pi}
$$

The plasma coupling for geons $\Gamma$ plays a very important role in the Microworld because it couples the "heat wave" and the "light wave" of the photon as:

$$
E=h_{G} \nu_{G}=16 \pi \alpha h^{*} \frac{\nu}{16 \pi \alpha}
$$

In this "core - shell" model of the photon the "core" is the "heat wave" surrounded by the "shell" creating the "light wave".

\section{The Barrier of the Determinacy}

In quantum mechanics, the uncertainty principle (also known as Heisenberg's uncertainty principle) represents a fundamental limit to the precision with which the experimental values for certain pairs can be experimentally achieved. Earle Hesse Kennard in 1927 derived the formal inequality relating the standard deviation of position $\sigma_{\mathrm{x}}$ and the standard deviation of momentum $\sigma_{\mathrm{p}}$ as:

$$
\sigma_{x} \sigma_{p} \geq \frac{\hbar}{2} \geq 5.27286 \ldots{ }^{*} 10^{-35} \mathrm{Js}
$$

For the case of the "core - shell" model of the photon we can approach the barrier B of the experimental determinacy limited by the amplitude difference of the super-elastic double-helix photon $\lambda / 2 \pi$ and the super-elastic double-helix geon $\lambda_{\mathrm{G}} / 2 \pi$. For the difference of the actions of photon $\mathrm{h}$ and the action of geon $\mathrm{h}_{\mathrm{G}}$ we can write: 


$$
B=\left(\frac{h}{2 \pi}-\frac{h_{G}}{2 \pi}\right)=\frac{h}{2 \pi}(1-16 \pi \alpha)=\frac{h}{2 \pi}\left(1-\frac{\alpha}{\Gamma}\right)=6.67749 \ldots{ }^{*} 10^{-35} \mathrm{Js}
$$

It might be interesting to estimate which barrier of the determinacy will be experimentally determined as the true limit used by Nature.

\section{Newton - Zwicky's Law of Cooling of Old Photons, Hubble Cooling Constant}

The "core-shell" model of photon with the geon creating a "heat wave" and the coupled "light wave" enables to analyze the cooling of that "old" photon using the Newton law of cooling. Newton's law of cooling states that the rate of heat loss of a body is directly proportional to the difference in the temperatures between the body and its surroundings.

The first model describing redshifts of old photons formulated Fritz Zwicky in 1929 in the same year as Edwin Hubble published his redshift data for old photons.

For the cooling of an old photon we can write:

$$
\frac{T(t)-T_{C M B}}{T(0)-T_{C M B}}=e^{-H_{0} t}
$$

where $\mathrm{T}(0)$ and $\mathrm{T}(\mathrm{t})$ are photon temperatures based on the Wien displacement law at time 0 and time $\mathrm{t}$ of that photon age. $\mathrm{T}_{\mathrm{CMB}}$ is the temperature of cosmic background given as $\mathrm{T}=2.725 \mathrm{~K}$ (e.g., Erich Regener predicted this temperature as $\mathrm{T}=2.8 \mathrm{~K}$ in 1933 , the precise value of the $\mathrm{CMB}$ was later determined by many Great Experimental Physicists). The constant $\mathrm{H}_{0}$ is the famous Hubble constant describing in this situation the cooling rate of those old photons.

Jaroslav Šesták (2020) recommended us to formulate the cooling constant in the Newton cooling law using the Biot and Fourier numbers in units $\mathrm{W} \mathrm{J}^{-1}$ (watt per joule) as:

$$
H_{0}=\frac{2 c^{2}}{k} \frac{\partial}{\partial t}\left(\frac{m}{T}\right)=2.331 \ldots{ }^{*} 10^{-18} W J^{-1}
$$

This Hubble cooling constant might be used for the analysis of redshift data of old photons during their cooling process using photon frequencies as:

$$
\frac{\nu(t)-\nu_{C M B}}{\nu(0)-\nu_{C M B}}=e^{-H_{0} t}
$$

This Hubble cooling constant might be used for the analysis of redshift data of old photons during their cooling process using photon wavelengths as:

$$
\frac{\frac{c}{\lambda(t)}-\frac{c}{\lambda(C M B)}}{\frac{c}{\lambda(0)}-\frac{c}{\lambda(C M B)}}=e^{-H{ }_{0} t}
$$

We want to pass this model into the hands of Readers of this Journal with a deeper knowledge of redshift data of old photons.

\section{Tolman Surface Brightness Test, Density of Geons}

The Tolman surface brightness test is one of cosmological tests that was first proposed in 1930 by Richard C. Tolman as a test of whether Universe is expanding or static. The surface brightness in a simple expanding Universe should decrease with the fourth power of $(z+1)$. The traditional "tired light" scenario proposed the decrease with the first power of $(z+1)$.

We can write the density $\rho(t)$ of the old cooling super-elastic double- helix geon as: 


$$
\rho(t)=\frac{m(t)}{V(t)}=\frac{m(t)}{\pi\left(\frac{\lambda(t)}{2 \pi}\right)^{2} \lambda(t)}=\frac{m_{0}(z+1)^{-1}}{\frac{\lambda_{0}^{3}(z+1)^{3}}{4 \pi}}=\frac{\rho(0)}{(z+1)^{4}}
$$

In this scenario the density of the cooling geon decreases with the fourth power of $(z+1)$, so as the observed brightness decreases with the fourth power of $(z+1)$.

A. Sandage and L.M. Lubin made their great experimental observation with the Hubble telescope in 2001 and confirmed the fourth power of $(z+1)$ dependence. Their data were interpreted in favor of the expanding Universe.

(Great Old Masters including Isaac Newton proposed to evaluate the density of "aether" and tried qualitatively to insert this effect into their models).

\section{Conclusions}

1. We have combined knowledge of Old Masters, New Masters, and Dissidents in order to newly formulate events observed with "heat waves" and "light waves".

2. We have introduced "Wien photopic peak" and "Wien scotopic peak" based on thermodynamic arguments.

3. We have decomposed the Planck distribution function in two parts.

4. Photon was modelled as two coupled oscillators - the "heat wave" and the "light wave".

5. The value for the geon action was found from the Beta Plasma.

6. The coupling constant was derived from the plasma coupling $\Gamma$.

7. The barrier B for the determinacy was formulated.

8. Hubble cooling constant describing cooling of old photons was inserted into the Newton - Zwicky law of cooling.

9. The density of old photons was formulated and checked with the Tolman surface brightness test prediction.

10. We need more experimental data for the events with "heat waves" and "light waves".

11. Nature might hide Her Beauty in plain sight protected by the mathematical camouflage.

12. We want to pass this model into hands of Readers of this Journal better educated in Mathematics, Physics and Thermodynamics.

\section{Acknowledgments}

This work was supported by the JP\&FŠ Agency (Contract Number 25g/1963), by the VZ\&MŠ Agency (Contract Number 16000/1989), by the GMS Agency (Contract Number 69110/1992), and by the FH\&ES Agency (Contract Number 1502/2020). We were supported by the contract numbers 28101918/2018, 58287/2019. We have found the valuable support on the web site www.wolframalpha.com with the corrections of used formulae.

\section{Conflict of interests}

The authors declare that there is no conflict of interests regarding the publication of this paper.

\section{References}

Anderson, P. R., \& Brill, D. R. (1997). Gravitational Geons Revisited. Arxiv: gr-qc/9610074v2.

Aoki et al. (2018). Massive Graviton Geons. Arxiv: 1710.05606v2. https://doi.org/10.1103/PhysRevD.97.044005

Apollonius of Perga. On the Cochlias. In Proclus, On L. Euclid (Ed.), Friedlein (Vol. 105, pp. 1-6).

Ashworth, R. A. (1998). Confirmation of Helical Travel of Light through Microwave Waveguide Analysis. Physics Essays, 11, 1-10. Retrieved from https://www.researchgate.net/publication/260829054_ Confirmation_of_Helical_Travel_of_Light_through_Microwave_Waveguide_Analyses; https://doi.org/10.4006/1.3025308

Bell, J. S. (1992). Six Possible Worlds of Quantum Mechanics. Foundations of Physics, 22, 1201-1215. https://doi.org/10.1007/BF01889711

Blåsjö, V. (2018). Mathematicians Versus Philosophers in Recent Work on Mathematical Beauty. Journal of Humanistic Mathematics, 8, 414-431. Retrieved from https://scholarship.claremont.edu/cgi/viewcontent.cgi? 
referer=https://www.google.com/\&httpsredir=1\&article=1380\&context=jhm; https://doi.org/10.5642/jhummath.201801.20

Boccaletti et al. (1970). Conversion of Photons into Gravitons and Vice Versa in a Static Electromagnetic Field. Il Nuovo Cimento, LXX, 129-146. https://doi.org/10.1007/BF02710177

Bohm, D. (1949). The Characteristics of Electrical Discharges. In A. Guthrie \& R. K. Wakkreling (Eds.), Magnetic Fields. New York: McGraw-Hill.

Bohm, D. (1952). A Suggested Interpretation of the Quantum Theory in Terms of Hidden Variables, I. Physical Review, 85, 166-179. https://doi.org/10.1103/PhysRev.85.166

Bohm, D. (1989). Quantum Theory. Dover Publications, ISBN-10: 9780486659695.

Boya, L. J. (2004). The Thermal Radiation Formula of Planck (1900). Arxiv: physics/0402064v1.

Boyer, T. H. (2019). Thermodynamics of the Harmonic Oscillator: Derivation of the Planck Blackbody Spectrum from Pure Thermodynamics. Eur. J. Phys., 40, 025101. https://doi.org/10.1088/1361-6404/aaf45b

Brackenridge, J. B. (1996). The Key to Newton's Dynamics: The Kepler Problem and the Principia. Berkeley: University of California Press. ISBN: 978-0520202177.

Brush, S. G. (1970). The Wave Theory of Heat: A Forgotten Stage in the Transition from the Caloric Theory to Thermodynamics. British Journal for the History of Science, 5, 145-167. https://doi.org/10.1017/S0007087400010906

Bultinck et al. (2010). The Origin of Bohm Diffusion, investigated by a Comparison of Different Modelling Methods. J. Physics D-Applied Physics, 43, 29-34. https://doi.org/10.1088/0022-3727/43/29/292001

Calculation of Blackbody Radiance. Retrieved from https://www.spectralcalc.com/blackbody/blackbody.html

Cohen et al. (2019). Realism and Causality I: Pilot Wave and Retrocausal Models as Possible Facilitators. Arxiv: $1902.05108 \mathrm{v} 2$.

Cohen, I. B. (1999). A Guide to Newton's Principia. The Principia: The Mathematical Principles of Natural Philosophy. Berkeley, CA, University California Press. ISBN: 978-0-520-08816-0.

Cohen, I. B., \& Smith, G. E. (Eds.) (2004). The Cambridge Companion to NEWTON. Cambridge University Press, Cambridge, ISBN 0-521-65696-6.

Cook, T. A. (1914). The Curves of Life. Constable and Company, London.

Cylindrical Helix. Retrieved from http://demonstrations.wolfram.com/SineAndCosineHelix/

Cylindrical Helix. Retrieved from http://mathworld.wolfram.com/Helix.html

Cylindrical Helix. Retrieved from https://en.wikipedia.org/wiki/Helix

Cylindrical Helix. Retrieved from https://www.mathcurve.com/courbes3d.gb/helicecirculaire/ helicecirculaire.shtml

Darrigol, O. (2012). A History of Optics. From Greek Antiquity to the Nineteenth Century. Oxford University Press. Oxford. ISBN-10: 0199644373.

De Broglie - Bohm Theory. Retrieved from https://en.wikipedia.org/wiki/De_Broglie\%E2\%80\%93Bohm_theory

De Broglie, L. (1927). Electrons et Photons: Rapport et Discussions du Cinquième Conseil de Physique tenu à Bruxelles du 24 au 29 Octobre 1927. Gauthier-Villars.

De Broglie, L. (1939). Matter and light: The New Physics (pp. 136-142). W.W: Norton CO., New York.

Deffner, S., \& Campbell, S. (2019). Quantum Thermodynamics: An Introduction to the Thermodynamics of Quantum Information. Morgan \& Claypool Publishers, ISBN: 978-1-64327-658-8. https://doi.org/10.1088/2053-2571/ab21c6

Delgado-Bonal, A. (2017). Entropy of Radiation: The Unseen Side of Light. Scientific Reports, 7, 1642. https://doi.org/10.1038/s41598-017-01622-6

Delgado-Bonal, A., \& Martin-Torres, J. (2016). Human Vision is Determined Based on Information Theory. Sci. Rep., 6, 36038. https://doi.org/10.1038/srep36038

Dennis, D. (1995). Historical Perspectives for the Reform of Mathematics Curriculum: Geometric Curve Drawing Devices and their Role in the Transition to an Algebraic Description of Functions. Dissertation at Cornell University. Retrieved from http://www.quadrivium.info/mathhistory/CurveDrawingDevices.pdf 
Duncan, A., \& Janssen, M. (2019). Constructing Quantum Mechanics: Volume 1: The Scaffold: $1900-1923$. Oxford University Press, ISBN: 978-0-19-884547-8. https://doi.org/10.1093/oso/9780198845478.001.0001

Dürer, A. (1525). Underweysung der Messung, mit dem Zirckel und Richtscheyt, in Linien, Ebenen und gantzen corporen. (Dürer's Plan for the Cylindrical Helix in a Staircase) Retrieved from https://commons.wikimedia.org/wiki/Category:Underweysung_der_Messung

Dürr, D., \& Teufel, S. (2009). Bohmian Mechanics: The Physics and Mathematics of Quantum Theory (Fundamental Theories of Physics. Springer, ISBN 10-3540893431. https://doi.org/10.1007/b99978_12

Einstein, A. (1905). On a Heuristic Point of View Concerning the Production and Transformation of Light. Annalen der Physik, 17, 132-148. https://doi.org/10.1002/andp.19053220607

Feynman, R. (1964). Quantum Behavior. Feynman Lectures, III(1). Retrieved fromhttp://www.feynmanlectures.caltech.edu/III_01.html

Fine Structure Constant. Retrieved from https://en.wikipedia.org/wiki/Fine-structure_constant

Ford, K., \& Wheeler, J. A. (2000). Geons, Black Holes, and Quantum Foam: A Life in Physics. W.W: Norton \& Company, ISBN-10: 0393319911.

Freire, O. (2003). Science and Exile: David Bohm, the Hot Times of the Cold War, and his Struggle for a New Interpretation of Quantum Mechanics. Retrieved from https://arxiv.org/ftp/physics/papers/0508/0508184.pdf

Freire, O. (2015). The Quantum Dissidents: Rebuilding the Foundations of Quantum Mechanics (1950-1990). With a Forword by S.S. Schweber. Springer, ISBN-10: 9783662446614.

Fried, M., \& Unguru, S. (2001). Apollonius of Perga's Conica: Text, Context, Subtext. Mnemosyne, Bibliotheca Classic. ISBN-10: 9004119779. https://doi.org/10.1163/9789004350991

Gant, de F. (1995). Force and Geometry in Newton's Principia. Princeton University Press, Princeton. ISBN 0-691-03367-6.

Gauthier, R. (2017). Entangled Double-Helix Superluminal Composite Photon Model Defined by Fine Structure Constant. Retrieved from https://www.researchgate.net/publication/320840733_Entangled_DoubleHelix_Superluminal_Composite_Photon_Model_Defined_by_Fine_Structure_Constant

Geminus of Rhodes: Cylindrical Helix. Retrieved from https://www-history.mcs.st-and.ac.uk/ Biographies/Geminus.html

Guicciardini, N. (2003). Reading the Principia: The Debate on Newton's Mathematical Methods for Natural Philosophy from 1687 to 1736. Cambridge University Press, Cambridge. ISBN-10: 0521544033.

Hadot, P. (2008). The Veil of Isis: An Essay on the History of the Idea of Nature. Belknap Press. ISBN-10: 0674030494.

Hall, A. R. (2015). Philosophers at War: The Quarrel Between Newton and Leibniz. Cambridge University Press. ISBN: 052152489X.

Hardy, L. (1992). On the Existence of Empty Waves in Quantum Theory. Physics Letters A, 167, 11-16. https://doi.org/10.1016/0375-9601(92)90618-V

Heald, M. A. (2003) Where is the "Wien Peak?" Am. J. Physics, 71, 1322-1323. https://doi.org/10.1119/1.1604387

Heat, T. L. (2015). Apollonius of Perga: Treatise on Conic Sections. Carruthers Press. ISBN-10: 1446021262.

Heat. Retrieved from https://en.wikipedia.org/wiki/Heat

Helical Electromagnetic Waves. (2011). Retrieved from http://blackholeformulas.com/files/EnM.html

Heron. (1912). Heronis Alexandrini opera quae supersunt omnia. Teubner, Leipzig, Ed. And translated into German by J.L. Heiberg.

Herschel, W. (1800). Experiments on the Refrangibility of the Invisible Rays of the Sun. Phil. Trans. Royal Soc., 90, 284-292. https://doi.org/10.1098/rstl.1800.0015

History of Thermodynamics. Retrieved from https://en.wikipedia.org/wiki/History_of_thermodynamics

Huygens, Chr. (1678). Traité de la Lumière, Leyden, Van der Aa. (In Treatise on Light, London: McMillan, 1912).

Interpretations of Quantum Mechanics. Retrieved from https://en.wikipedia.org/wiki/Interpretations_of_quantum_mechanics 
Johnson, C. (2012). Mathematical Physics of Blackbody Radiation. Retrieved from http://www.csc.kth.se/ cgjoh/ambsblack.pdf

Jungnickel, C., \& McCormmach, R. R. (1986). Intellectual Mastery of Nature: The Now Mighty Theoretical Physics, 1870-1925 v. 2: Theoretical Physics from Ohm to Einstein. University of Chicago Press, ISBN-10: 0226415848 .

Kuhn, T. (1987). Black-Body Radiation and the Quantum Discontinuity, 1894-1912. University of Chicago Press, ISBN-10: 0226458008.

Kvasz, L. (2012). Galileo, Descartes, and Newton-Founders of the Language of Physics. Acta Physica Slovaca, 62, 519-614. Retrieved from http://www.physics.sk/aps/pubs/2012/aps-12-06/aps-12-06.pdf

Laird, W. R., \& Roux, S. (Eds.) (2008). Mechanics and Natural Philosophy before the Scientific Revolution. Springer. ISBN 978-90-481-7491-1. https://doi.org/10.1007/978-1-4020-5967-4

Levitt, L. S. (1978). Is the Photon a Double Helix? Lettere al Nuovo Cimento, 21, 222-223. https://doi.org/10.1007/BF02822254

Lewis, P. J. (2007). Empty Waves in Bohmian Quantum Mechanics. British Journal for the Philosophy of Science, 58, 787-803. https://doi.org/10.1093/bjps/axm039

Mancosu, P., \& Arana, A. (2010). Descartes and the Cylindrical Helix. Historia Mathematica, 37, 403-427. Retrieved from https://www.sciencedirect.com/science/article/pii/S0315086009000949; https://doi.org/10.1016/j.hm.2009.10.006

Maor, E., \& Jost, E. (2014). Beautiful Geometry. Princeton University Press, Princeton. ISBN-13:978-0-691-15099-4.

Mareš et al. (2008). Phenomenological Approach to the Caloric Theory of Heat. Thermochimica Acta, 474, 16-24. https://doi.org/10.1016/j.tca.2008.05.001

Mareš, J. J. (2015). Do we know what the Temperature is? Journal of Thermal Analysis and Calometry, 120, 223-230. Retrieved from https://arxiv.org/ftp/arxiv/papers/1604/1604.05563.pdf; https://doi.org/10.1007/s10973-015-4490-7

Mareš, J. J., \& Šesták, J. (2007). Caloric Theory of Heat. Slide show. Retrieved from https://www.slideserve.com/libitha/caloric-theory-of-heat

Mareš, J. J., Hubík, P., \& Špička, V. (2017). On Relativistic Transformation of Temperature. Fortschr. Phys., 65, 1700018. https://doi.org/10.1002/prop.201700018

Marr, J. M., \& Wilkin, F. P. (2012). A Better Presentation of Planck's Radiation Law. Arxiv: 1109.3822v3.

Miranda, E. N. (2019). Schrödinger and Planck Oscillators: not Quite the Same Physics. Retrieved from https://www.researchgate.net/publication/335978590_Schrodinger_and_Planck_oscillators_not_quite_the_s ame_physics

Nauenberg, M. (1993). Newton's Early Computational Method for Dynamics. Retrieved from https://core.ac.uk/download/pdf/82476251.pdf

Nauenberg, M. (2018a). Newton's Graphical Method for Central Force Orbits. Am. J. Phys., 86, 765-771. https://doi.org/10.1119/1.5050620

Nauenberg, M. (2018b). Visiting Newton's Atelier before the Principia, 1679-1684. Arxiv: 1805.06871v. https://doi.org/10.1080/00033790.2019.1566497

Newton, I. (1687). The Principia. Mathematical Principles of Natural Philosophy. Translated by I.B. Cohen and A. Whitman. University California Press, Berkeley. ISBN 978-0-520-08816-0.

Newton, I. (1704). Optics: Or, a treatise of the reflections, refractions, inflexions, and colors of light. Also two treatises of the species and magnitude of curvilinear figures. Palo Alto, Calif.: Octavo, ISBN 1-891788-04-3. https://doi.org/10.5479/sil.302475.39088000644674

Overduin, J. M. (2003). Eyesight and the Solar Wien Peak. Am. J. of Physics, 71, 216-219. https://doi.org/10.1119/1.1528917

Perry, G. P., \& Cooperstock, F. I. (1998). Stability of Gravitational and Electromagnetic Geons. Arxiv: gr-qc/9810045v1. 
Pilot Wave Theory and Quantum Realism. (2016). Space Time, PBS Digital Studios. Retrieved from https://www.youtube.com/watch?v=RlXdsyctD50

Pilot Wave Theory. Retrieved from https://en.wikipedia.org/wiki/Pilot_wave_theory

Pladevall, X. O., \& Mompart, J. (2019). Applied Bohmian Mechanics: From Nanoscale Systems to Cosmology (2nd ed.). Jenny Stanford Publishing, ISBN 10-9814800104.

Planck, M. (1901). On the Law of Distribution of Energy in the Normal Spectrum. Annalen der Physik, 4, 553. https://doi.org/10.1002/andp.19013090310

Planck, M. (1914). The Theory of Heat Radiation, Philadelphia. P. Blakiston's Son \& Co., California.

Planck, M., \& Bohr, N. (2019). Quantum Theory (Great Works that Shape Our World). Amazon, ISBN-10: 1787556824.

Plasma Parameter (Coupling Parameter). Retrieved from https://en.wikipedia.org/wiki/Plasma_parameter

Power, E. A., \& Wheeler, J. A. (1957). Thermal Geons. Rev. Mod. Phys., 29, 480. https://doi.org/10.1103/RevModPhys.29.480

Regener, E. (1933). Der Energiestrom der Ultrastrahlung. Zeit. Phys., 80, 666-669. https://doi.org/10.1007/BF01335703

Riemann, K. U. (1991). The Bohm Criterion and the Sheath Formation. J. Phys. D, Appl. Phys., 24, 493-518. https://doi.org/10.1088/0022-3727/24/4/001

Robitaille, P. M., \& Crothers, S. J. (2015). "The Theory of Heat Radiation" Revisited: A Commentary on the Validity of Kirchhoff's Law of Thermal Emission and Max Planck's Claim of Universality. Progress in Physics, 11, 120-132.

Rothleitner, C., \& Schlamminger, S. (2017). Invited Review Article: Measurements of the Newtonian Constant of Gravitation. G. Rev. Sci. Instrum., 88, 111101-1. https://doi.org/10.1063/1.4994619

Roveli, C. (2018). Physics Needs Philosophy. Philosophy Needs Physics. Found. Phys. 48, 481-491. Retrieved from https://arxiv.org/ftp/arxiv/papers/1805/1805.10602.pdf; https://doi.org/10.1007/s10701-018-0167-y

Sandage, A., \& Lubin, L. M. (2001). The Tolman Surface Brightness Test for the Reality of Expansion. Astrophysical Journal, 121, 2271-2288. 121, 2289-2300. 122, 1071-1083. 122, 1084-1103. https://doi.org/10.1086/320394

Sanduk, M. I. (1997). The Factor 1/16 of Bohm Diffusion. Indian Journal of Physics, 71B, 495-502.

Schlamminger, S. (2017). Quantifying the Quantum. Nature Physics, 13, 618. https://doi.org/10.1038/nphys4158

Schumacher, A. (1999). Systematische Untersuchungen zur Messung der Newtonschen Gravitationskonstanten mit einem Pendelresonator. PhD Thesis, University of Wuppertal, WUB-DIS-99-13.

Schwinger, J. (1976). Gravitons and Photons: The Methodological Unification of Source Theory. General Relativity and Gravitation, 7, 251-256. https://doi.org/10.1007/BF00768525

Seager, W. (2018). The Philosophical and Scientific Metaphysics of David Bohm. Entropy, 20, 493. https://doi.org/10.3390/e20070493

Šesták, J. (2005). Science of Heat and Thermophysical Studies.

Šesták, J. (2019). Do we really know what temperature is: From Newton' cooling law to an improved understanding of thermal analysis. J. Thermal Analysis and Calorimetry. https://doi.org/10.1007/s10973-019-09149-w

Soffer, B. H., \& Lynch, D. K. (1999). Some paradoxes, Errors, and Resolutions Concerning the Spectral Optimization of Human Vision. Am. J. Phys., 67, 946-953. https://doi.org/10.1119/1.19170

Stávek, J. (2019). Super-Elastic Double-Helix Model of Photon. Huygens-de Broglie Particle on the Helical Path Guided by the Newton-Bohm Entangled Helical Evolute. Quantum of Magnetic Flux Based on the Mathematical Beauty of Newton, Lorentz, Einstein, Dirac, Gell-Mann, Schwinger, Polchinski and Witten (16.06.2019). Appl. Phys. Res., 11, 40-51. https://doi.org/10.5539/apr.v11n4p40

Stávek, J. (2020). Squeezing of the Super-Elastic Double-Helix Photon in the Gravitational Field (Hidden in Very Well- Known Old Formulae). Pound-Rebka-Snider Effect Studied by the Advanced LIGO Instrument, Pioneer Anomaly and CMB (Cosmic Microwave Background). (23.11.2019). Applied Physics Research, 12, 8-18. https://doi.org/10.5539/apr.v12n1p8 
Stávek, J. (2020). Stretching of the Super-Elastic Double-Helix Geon. Wheeler's Thermal Geons as Quanta of Heat and Momentum. Bohm's Diffusion and the Heating of the Solar Corona and Heating of the Earth-Geon Engineering. Milgrom-Verlinde Constant. Mareš-Šesták Constant. Applied Physics Research, 12, 12-24. https://doi.org/10.5539/apr.v12n2p12

Sternberg, N., \& Godyak, V. (2007). The Bohm Plasma-Sheath Model and the Bohm Criterion Revisited. IEEE Transactions on Plasma Science, 35, 1341-1349. https://doi.org/10.1109/TPS.2007.905944

Stewart, S. M. (2011). Wien Peaks and the Lambert W Function. Revista Brasileira de Ensino de Física, 33, 3308-01-3308-6. https://doi.org/10.1590/S1806-11172011000300008

Stewart, S. M. (2012). Spectral Peaks and Wien's Displacement Law. J. Thermophysics and Heat Transfer, 26, 689-691. https://doi.org/10.2514/1.T3789

Stewart, S. M., \& Johnson, R. B. (2017). Blackbody Radiation. A History of Thermal Radiation Computational Aids and Numerical Methods, CRC Press, ISBN-13: 978-1-4822-6312-1.

Temperature. Retrieved from https://en.wikipedia.org/wiki/Temperature

Tombe. F. D. (2019). The 1855 Weber-Kohlrausch Experiment (The Speed of Light). The General Science Journal. Retrieved from https://www.scribd.com/document/294114501/The-1855-Weber-Kohlrausch -Experiment-The-Speed-of-Light

Tran, M. (2020). Planck's and Callendar's Blackbody Radiation Formulas and their Fitness to Experimental Data. Eur. J. Phys., 41, 025102. Retrieved from https://iopscience.iop.org/article/10.1088/1361-6404/ab513b/pdf; https://doi.org/10.1088/1361-6404/ab513b

Uncertainty Principle. Retrieved from https://en.wikipedia.org/wiki/Uncertainty_principle

Verlinde, E. P. (2011). On the Origin of Gravity and the Laws of Newton. JHEP, 4, 29. Arxiv: 1001.0785. https://doi.org/10.1007/JHEP04(2011)029

Walleczek, J., Grossing, G., \& Pylkkanen, P. (2019). Emergent Quantum Mechanics: David Bohm Centennial Perspectives. Mdpi AG, ISBN-10:3038976165. https://doi.org/10.3390/e21020113

Watson, J. D. (2001). The Double Helix: A Personal Account of the Discovery of the Structure of DNA. Touchstone, ISBN-10: 9780743216302.

Wheeler, J. A. (1955). Geons. Physical Review, 97, 511. https://doi.org/10.1103/PhysRev.97.511

Wheeler, J. A. (1957). On the Nature of Quantum Geometrodynamics. Annals of Physics, 604-614. https://doi.org/10.1016/0003-4916(57)90050-7

Wien, W. (1897). On the Division of Energy in the Emission Spectrum of a Black-Body. Phil. Mag., 43, 214-220. https://doi.org/10.1080/14786449708620983

Wien's Displacement Law. Retrieved from https://en.wikipedia.org/wiki/Wien\%27s_displacement_law

Wilczek, F. (2016). Physics in 100 years. Physics Today, 69, 32-39. https://doi.org/10.1063/PT.3.3137

Williams, G. (2019). Unravelling the Double Helix. The lost Heroes of DNA. Weidenfeld \& Nicholson, ISBN-10: $147460935 \mathrm{X}$.

Wu et al. (2019). Progress in Precise Measurements of the Gravitational Constant. Annalen der Physik (Berlin), 531, 1900013. https://doi.org/10.1002/andp.201900013

Zank et al. (2004). Perpendicular Diffusion Coefficient for Charged Particles of Arbitrary Energy. J. Geophysical Research, Space Physics, 109(A4). https://doi.org/10.1029/2003JA010301

Zhang, Z. M., \& Wang, X. J. (2010). Unified Wien's Displacement Law in Terms of Logarithmic Frequency or Wavelength Scale. Journal of Thermophysics and Heat Transfer, 24, 222-224. https://doi.org/10.2514/1.45992

\section{Copyrights}

Copyright for this article is retained by the author(s), with first publication rights granted to the journal.

This is an open-access article distributed under the terms and conditions of the Creative Commons Attribution license (http://creativecommons.org/licenses/by/4.0/). 